\title{
Congenital transmission of Trypanosoma cruzi in central Brazil. A study of 1,211 individuals born to infected mothers
}

\author{
Alejandro O Luquetti ${ }^{+}$, Suelene Brito do Nascimento Tavares, \\ Liliane da Rocha Siriano, Rozângela Amaral de Oliveira, Dayse Elizabeth Campos, \\ Cicilio Alves de Morais, Enio Chaves de Oliveira
}

Núcleo de Estudos de Doença de Chagas, Universidade Federal de Goiás, Goiânia, GO, Brasil

\begin{abstract}
Transmission of Trypanosoma cruzi during pregnancy is estimated to occur in less than $20 \%$ of infected mothers; however, the etiopathogenesis is not completely understood. The Centre for Studies on Chagas Disease provides confirmation of $\mathrm{T}$. cruzi infection for individuals living in central Brazil. In this retrospective hospital-based study, all requests for diagnosis of T. cruzi infection in individuals less than 21 years old from 1994-2014 were searched. We end with 1,211 individuals and their respective infected mothers. Congenital transmission of infection was confirmed in 24 individuals (2\%) in central Brazil, an area where the main T. cruzi lineage circulating in humans is TcII. This low prevalence of congenital Chagas disease is discussed in relation to recent findings in the south region of Brazil, where $T \mathrm{cV}$ is the main lineage and congenital transmission has a higher prevalence (approximately 5\%), similar to frequencies reported in Argentina, Paraguay and Bolivia. This is the first report to show geographical differences in the rates of congenital transmission of $\mathrm{T}$. cruzi and the relationship between the prevalence of congenital transmission and the type of Tc prevalent in each region.
\end{abstract}

Key words: Chagas disease - Trypanosoma cruzi - congenital transmission - geographical differences - familial studies

Perinatal transmission of Trypanosoma cruzi is estimated to occur in a low percentage of infected mothers (less than 20\%); the reasons for the low prevalence of this route of transmission are not clearly understood. Few large studies are available and those that have been conducted are mainly from three countries: Argentina, Bolivia and Paraguay, where the congenital transmission rate is 5\% (4.1-6\%) (Howard et al. 2014). Currently, as a consequence of migration, Chagas disease is widespread, mainly in some countries of Europe and the United States of America (USA). Congenital transmission has accompanied this migration, but has mainly been observed in Spain (Barona-Vilar et al. 2012) and Switzerland (Jackson et al. 2009) among almost exclusively Bolivian mothers; congenital transmission rates, as expected, are similar to Bolivian estimates. It is noteworthy that few cases of congenital transmission have been reported from the USA, even though the number of infected immigrants to the USA, mainly from Mexico, is higher than in Spain (Schmunis 2007).

In Brazil, several surveys have been performed [reviewed recently by Martins-Melo et al. (2014)] and figures are consistently lower than those found in other South Cone countries, with a rate of approximately

doi: 10.1590/0074-02760140410

+ Corresponding author: luquetti@hc.ufg.br

Received 1 November 2014

Accepted 3 February 2015
$1 \%$. The reasons for this variation have not yet been explained. A recent survey has shed some light on this subject; a study of more than 100,000 samples from children younger than five years old, which covered all areas of Brazil (Luquetti et al. 2011) except the state of Rio de Janeiro (RJ), aimed to detect vector-borne transmission after insecticide spraying performed before these children were born. As a secondary result of this study, 20 congenital cases were found, $60 \%$ of which were from the state of Rio Grande do Sul (RS). In this region of Brazil, a different lineage of $T$. cruzi is prevalent (TcV), making this area similar to those previously cited countries where the same type of T. cruzi is also prevalent and a higher transmission rate $(5 \%)$ has been reported.

In our view, these data support the existence of decisive geographical differences in $T$. cruzi transmission. Specifically, the supporting data include the large numbers of infected mothers in regions where $\mathrm{TcV}$ is prevalent, who experience an average transmission rate of 5\% (4-6\%) and the low numbers of infected mothers in Brazil, which experiences a lower congenital transmission prevalence of approximately $1 \%$. Additional supporting data are the low number of cases reported in Mexico and the USA despite the presence of a large number of infected women of childbearing age, as well as the recent finding of striking differences within Brazil, with five-10 times more congenital cases occurring in a single state where a different Tc lineage is prevalent than in any other region.

The objective of this report is to ascertain the transmission rate of T. cruzi in children born from mothers who acquired the infection in central Brazil, an area of high TcII prevalence, to reinforce the data of the recent serological survey (Luquetti et al. 2011) that found lower transmission rates in all municipalities of Brazil exception the RS. 


\section{SUBJECTS, MATERIALS AND METHODS}

Sample population - This hospital-based study was performed using the database from the Chagas disease laboratory of the Centre for Studies on Chagas Disease (NEDoC), which started in 1978 and provides clinical and laboratory diagnoses for this infection. The population referred to NEDoC for diagnosis derives from the Clinics Hospital [a teaching hospital at the Federal University of Goiás (HC-UFG), Brazil], blood banks in the state of Goiás (GO), private practices and a screening program for all pregnant women living in $\mathrm{GO}$ (operating since 2004) (Botelho et al. 2008, Gomes Filho et al. 2009, Siriano et al. 2011). In this screening program, all pregnant women confirmed to be positive for Chagas disease are requested to bring their child for testing six months after birth. In addition, all women with confirmed infections who have children are also requested to bring them to be tested for Chagas disease (Carlier et al. 2011). All serum samples are subjected to either three or four conventional serological tests: indirect immunofluorescence (IIF) (in house with BioMérieux conjugate, France), indirect haemagglutination (IHA) (Wiener, Argentina), ELISA (Biomanguinhos-Fiocruz, Brazil) and ELISA (Grupo Bios, Chile). Samples are stored indefinitely in frozen aliquots $\left(\right.$ at $\left.-20^{\circ} \mathrm{C}\right)$ and thawed when needed.

Selection of sera - We searched our records of 20,667 sera for those belonging to individuals less than 21 years old that were seen between November 1994-October 2014 and we identified 2,167 sera fitting these criteria. This period corresponds to the start of the NEDoC out-patient clinic. Subsequently, we linked the cases to their respective mothers and found 1,361 case-mother pairs. Pairs were excluded if they had any of the following: mother with negative serology $(n=74)$, mother with dubious serology $(\mathrm{n}=10)$, mother already given specific treatment $(n=4)$, child from whom we had only a sample of cord blood or blood collected before six months of age $(n=$ 44), child with positive serology who lived in an endemic area where vector transmission could not be ruled out (n $=14)$ or child who received a blood transfusion $(\mathrm{n}=3)$. After the exclusions, we had 1,211 pairs of sera from children and their mothers with confirmed infections.
Exclusion of 150 pairs did not modify the profile of the case population, which had a mean age of 7.4 years and was $50.7 \%$ male.

For cases where the diagnosis was unclear, an aliquot of serum was separated and all serologic tests were repeated. Inconclusive serology was defined as results including one or more positive test, one or more negative test and one or more borderline test.

Diagnosis of congenital transmission was made either by direct parasitological methods (in the newborn) or by positive serology of all four tests after four months of age. Exclusion of congenital transmission was determined by a negative serology at any age from a child/young adult born from a mother with confirmed infection.

All mothers completed a questionnaire, which collected information on the municipality where each mother was born and the subsequent places where they lived.

Statistical analysis - We provide descriptive statistics for population characteristics and the frequency of congenital transmission. Comparison of categorical variables was performed by Pearson's test. Continuous variables were compared using Student's $t$ test. In all statistical tests, the alpha error level was set at 5\%.

Ethics - Institutional Review Board approval was obtained for all study procedures at the HC-UFG.

\section{RESULTS}

Family study - After exclusions, though some mothers' infections were not obvious, 1,211 pairs of individuals less than 21 years old and their mothers, who were proven to be infected by four different serological tests, were found.

There was no predominant sex among the young individuals (591 male and 573 female) and their mean age was 7.4 years old (age range: 110 days - 20 years old). The distribution of age is shown in Table I. In 23 cases, the sex of the child was not determined because the samples were received with only the name of the mother (i.e., "newborn of MMS"). These children were not seen again at the NEDoC.

Children without transmission - In 1,187 samples from children, serological results were negative. These

TABLE I

Children: distribution by age - Clinics Hospital, Federal University of Goiás, Goiânia, Goiás, Brazil, 1994-2014

\begin{tabular}{|c|c|c|c|c|c|c|c|}
\hline \multirow[b]{2}{*}{$\begin{array}{l}\text { Age group } \\
\text { (years) }\end{array}$} & \multicolumn{3}{|c|}{ No transmission } & \multicolumn{3}{|c|}{ Transmission } & \multirow[b]{2}{*}{ Total } \\
\hline & $\begin{array}{l}\text { Children/ } \\
\text { young adults } \\
\text { (n) }\end{array}$ & $\begin{array}{l}\text { Gender } \\
\text { F/M } \\
\text { (n) }\end{array}$ & $\begin{array}{l}\text { Mean age } \\
\text { (years) }\end{array}$ & $\begin{array}{l}\text { Congenital } \\
\text { transmission } \\
\text { (n) }\end{array}$ & $\begin{array}{c}\text { Gender } \\
\text { F/M } \\
\text { (n) }\end{array}$ & $\begin{array}{c}\text { Mean age } \\
\text { (years) }\end{array}$ & \\
\hline $0-1$ & 266 & $107 / 136$ & 0.7 & 4 & $1 / 3$ & 0.4 & 270 \\
\hline $1.1-12$ & 610 & $306 / 304$ & 6.3 & 9 & $5 / 4$ & 4.8 & 619 \\
\hline $13-20$ & 311 & $160 / 151$ & 15.1 & 11 & $6 / 5$ & 17.5 & 322 \\
\hline Total & 1,187 & $573 / 591$ & 7.4 & 24 & $12 / 12$ & 9.9 & 1,211 \\
\hline
\end{tabular}

F: female; M: male. 
results were stratified by age into newborns $(<1$ year old), children (up to 12 years old) and young adults (1320 years old) (Table I).

Among the newborns $(n=266)$, a second collection of blood was required in 71 individuals because the serum was from cord blood or was taken before six months of age. It should be emphasised that all blood collected before six months of age showed antibodies against $T$. cruzi, even in cases where the antibodies disappeared in a later, second collection of blood. Therefore, passive transference was demonstrated. This was clear from the high antibody titres in blood taken at one-two months of age. In some cases, if the first collection was at three-four months, one or more serological reactions was negative or inconclusive, indicating a decay in antibody titres, which was confirmed on a second collection of blood after six months of age. As already explained, mothers with inconclusive serology results were excluded.

Among those children who had only a single collection taken, the youngest was 110 days of age at the collection time and two other cases were five months of age (160 and 178 days). The remaining single collection children were six months of age or older. Each of these cases was carefully evaluated to reach a definite diagnosis. For example, the youngest case (110 days of age) had two negative tests (ELISA and IHA), an IIF with a titre of 1/20 (inconclusive) and a positive Wiener ELISA recombinant test, with an index 1.2 times higher than the cut-off optical density (OD). Therefore, the overall testing results were inconclusive for this individual. However, in comparing the results with those of the mother, it was found that she had low antibody titres, as follows: ELISA 1.4 times higher than the cut-off OD, IIF 1/320, IHA $1 / 320$ and ELISA Wiener recombinant 7.1 times higher than the cut-off OD. These titres, though low, were several times higher than those of the son; thus, we concluded that his serology was negative.

For the second group of children (1-12 years old, $\mathrm{n}$ $=610$ ), a single collection of blood was enough to show no antibodies against $T$. cruzi. Most cases were clearly negative, but one of the tests occasionally showed a borderline reactivity. In four cases, one test was positive but the other three were negative, confirming the absence of specific antibodies.

For the third group of individuals (over 12 years old, $\mathrm{n}=311$ ), a single collection of blood was also sufficient and no cases of positivity in only one of the four tests was observed.

Children with transmission - Among the 1,211 pairs of individuals and their mothers, antibodies were present in 24 individuals and in their respective mothers. All of these 24 individuals lived in urban areas and had not received previous transfusions, thus they were classified as having congenital transmission of parasites from their mothers. This result indicates a $1.98 \%$ rate of transmission (Table I).

These 24 cases had mean age of 9.9 years old and $50 \%$ were female. The diagnosis was performed by the finding of parasites in two cases, one at 13 days of age and the other at 58 days of age (Table II, cases 1, 3). Interestingly, a search of parasites was performed in another 38 newborns because they were born from infected mothers, with negative results. Later, all of these cases proved to be the result of the passive transference of maternal antibodies.

Regarding age at time of diagnosis, four cases were less than one year old, nine were one-10 years old and 11 were older than 12 years old. Other demographic characteristics, diagnostic method, mother's origin, siblings, electrocardiogram result, treatment and follow up are shown in Table II. Interestingly, two cases (cases 4, 8) were from the same mother, who was born in a different state, RS, where the prevalence of congenital transmission is apparently high. As all other mothers were born and lived in central Brazil, the real transmission rate in mothers from this region was 22 cases out of 1,209 pairs, which makes the rate of transmission for central Brazil even lower $(1.8 \%)$.

Most cases were diagnosed via positive serology, which was confirmed by several techniques. Only two cases were diagnosed because of the presence of parasites (Table II). Newborns were sent to NEDoC by a paediatrician, whereas some of the young adults came as blood donors after being detected by screening at the blood bank. Most of the female young adults were detected by the state program for pregnant women $(n=8)$. Mothers of several of the congenital cases brought their other children for testing; however, most of them were not infected. The single exception was the mother born in RS, who contributed two congenital cases.

Regarding the symptoms in these individuals, most of them were asymptomatic and had normal electrocardiogram results $(n=15)$ (Table II). Nevertheless, severe cardiopathy was diagnosed in three individuals; two of them, aged 14 and 18 years old, later died.

Specific treatment was offered in all infected cases that returned for their results. Young adults frequently did not return and declined further follow up when contacted. Some mothers did not bring their children back or refused treatment. For those who started benznidazole, some were lost to follow up. Of the successfully treated cases, two were cured (cases 1, 7), with negative serology after four and two years of follow up, respectively. Another two treated individuals still have positive serology at high titres, even after seven and eight years after treatment.

Mothers - Many mothers contributed more than one child to this study. The number of individuals recorded was 1,211 , but the number of mothers was 678 (Table III). Some mothers contributed up to six children. When mothers who contributed more than three children $(\mathrm{n}=$ 34) and their 149 respective children were excluded, the proportion of the numbers of children/mothers remained similar (1.79 and 1.65, respectively).

To determine the location of infection in the mothers, the geographical distribution of the 678 mothers was recorded. Most of them lived their childhood in the same endemic region and after reaching eight-10 years of age, moved to a large city. More mothers were born (and likely infected) in the state of Bahia (BA) (57\%) than in GO (31\%) (Table IV) and there were also mothers from other Brazilian states and a Bolivian mother. Interestingly, the mothers who transmitted the infection were mainly born in $\mathrm{GO}(66 \%)$. 


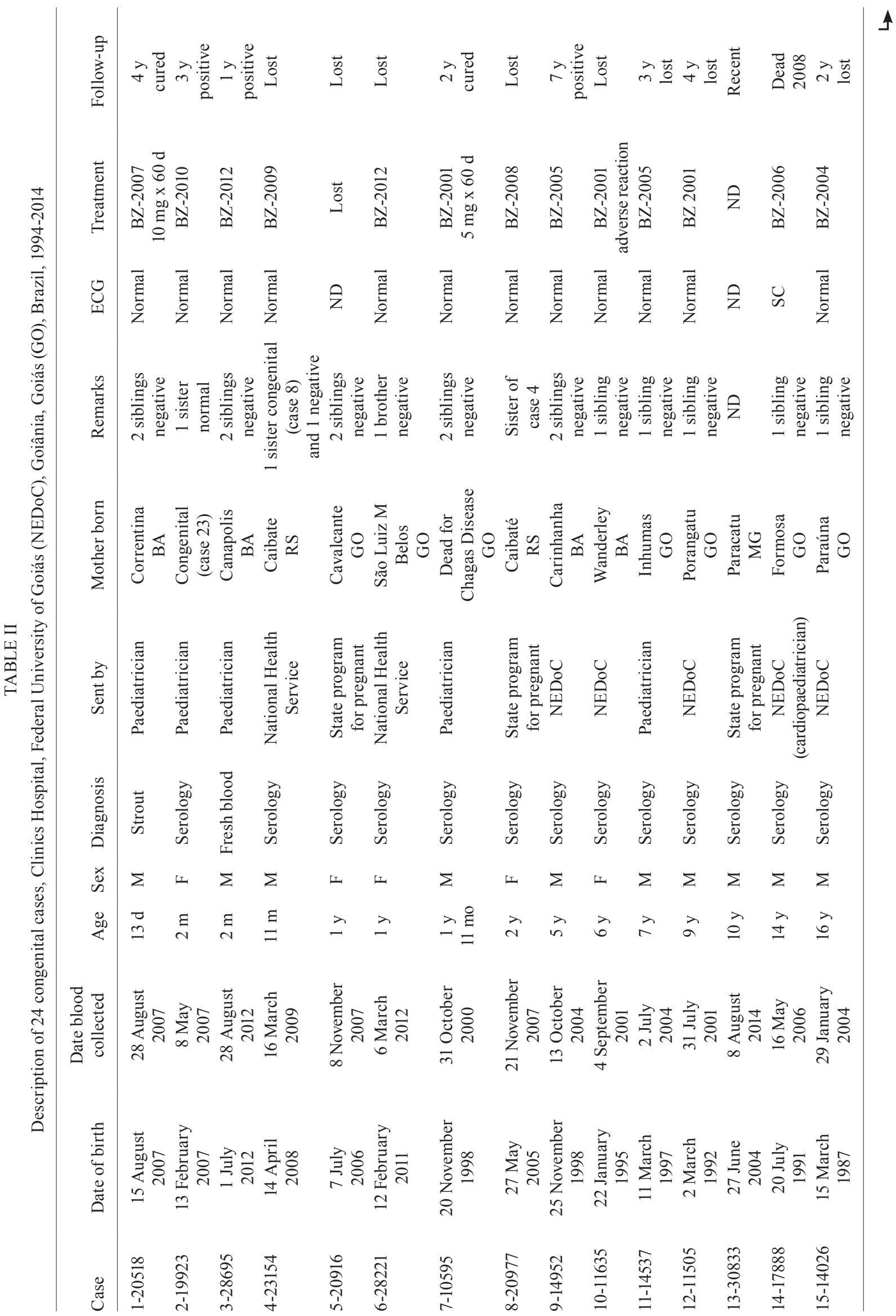




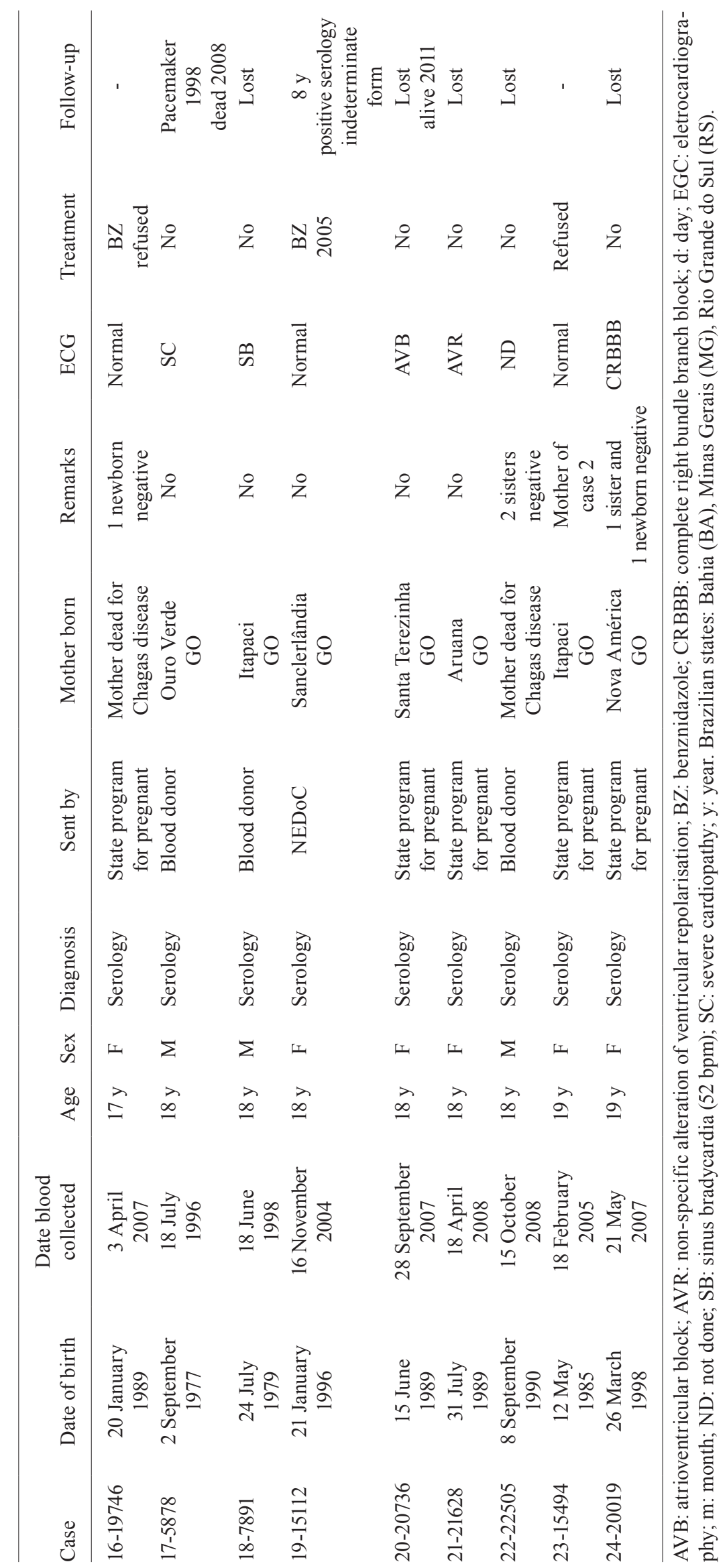


TABLE III

Number of mothers and children studied - Clinics Hospital, Federal University of Goiás, Goiânia, Goiás, Brazil, 1994-2014

\begin{tabular}{lccc}
\hline $\begin{array}{l}\text { Children/ } \\
\text { mother } \\
\text { (n) }\end{array}$ & $\begin{array}{c}\text { Mothers } \\
\text { (n) }\end{array}$ & $\begin{array}{c}\text { Children } \\
\text { (n) }\end{array}$ & $\begin{array}{c}\text { Children } \\
\text { congenital } \\
\text { (n) }\end{array}$ \\
\hline 1 & 319 & 319 & 8 \\
2 & 232 & 464 & 6 \\
3 & 93 & 279 & $10^{a}$ \\
4 & 24 & 96 & - \\
5 & 7 & 35 & - \\
6 & 3 & 18 & - \\
\hline Total & 678 & 1,211 & 24 \\
\hline
\end{tabular}

$a$ : two from the same mother.

\section{DISCUSSION}

This is a detailed study of 1,211 pairs of individuals and their mothers who were serologically confirmed to be infected with $T$. cruzi. All serology was carefully performed with at least four different techniques of different principles. Inconclusive results, usually observed in $1.4 \%$ of serological tests for detection of T. cruzi infection (Luquetti \& Schmuñis 2010), were excluded. When the concentration of antibodies was low in one of the tests, aliquots of sera were separated and all tests were performed again. There were three population groups: mothers with high antibody titres, individuals born from these mothers with a clear negative serology and a small group of 22 sera from individuals less than 21 years old with positive results and high antibody titres. In two cases, parasites were found with direct tests; these individuals were at an age where maternal antibodies were present as well.

A questionnaire was administered to each mother at the time blood was taken at NEDoC to determine the place in which they were born, how many years they lived there and the subsequent places in which they lived, as well as the time spent in each municipality and the residence at present. From each mother, a record for the place in which they probably acquired the infection was created, chiefly considering the first 10 years of life. Most of the mothers remained in the same place during childhood (data not shown). In a few cases where mothers had not lived in endemic areas, there was a suspicion that some could have acquired Chagas disease by a congenital mechanism. In four such instances, it was possible to collect blood from the mother (grandmother of the child) and congenital transmission was confirmed (data not shown). Two of the mothers who acquired the infection congenitally contributed their own congenitally infected children, supporting the idea of second generation congenital transmission (Carlier \& Truyens 2010).

From the populations with conclusive results, i.e., presence or absence of antibodies against $T$. cruzi (or parasites in 2 newborns), a group of 24 was labelled as resulting from congenital transmission. The observed rate of transmission by this mechanism was $2 \%$. Taking into account that one mother was born in another state (RS) and contributed with two of these cases, the rate of transmission from mothers born in states other than RS, mainly in central Brazil, was $1.8 \%$.

Studies on congenital transmission are difficult to perform because the rate is low, below $10 \%$. Therefore, it is necessary to survey hundreds of mothers to select those infected. Study design also depends on the prevalence of Chagas infection (OMS/OPS 2006). If the expected prevalence is $5 \%$ (high), it is necessary to look for 2,000 pregnant women to find 100 infected and less

TABLE IV

Geographical origin of mothers where acquired the infection - Clinics Hospital, Federal University of Goiás, Goiânia, Goiás (GO), Brazil, 1994-2014

\begin{tabular}{|c|c|c|c|c|}
\hline Origin & $\begin{array}{c}\text { Main } \\
\text { microregions }^{a}\end{array}$ & $\mathrm{n}(\%)$ & $\begin{array}{l}\text { Congenital } \\
\text { transmission } \\
\text { (n) }\end{array}$ & Proportion \\
\hline BA & $2925-2926-2930$ & $389(57.4)$ & 4 & 16.6 \\
\hline GO & $5201-5206-5212$ & $210(31)$ & 16 & 66.7 \\
\hline MG & $3126-3129$ & $31(4.6)$ & 1 & 4.2 \\
\hline TO & $1714-1715$ & $14(2.1)$ & 1 & 4.2 \\
\hline Northeast Region & $\mathrm{PB}, \mathrm{CE}, \mathrm{PE}, \mathrm{RN}, \mathrm{AL}$ & $18(2.7)$ & - & - \\
\hline Southeast Region & $\mathrm{PR}, \mathrm{RS}$ & $2(0.3)$ & 2 & 8.3 \\
\hline Other states & MS, MT, PA & $6(0.9)$ & - & - \\
\hline Bolivia & Santa Cruz & $1(0.1)$ & - & - \\
\hline No information & - & $7(1)$ & - & - \\
\hline Total & - & $678(100)$ & 24 & 100 \\
\hline
\end{tabular}

a: Brazilian states (IBGE 2014): Alagoas (AL), Bahia (BA), Ceará (CE), Mato Grosso (MT), Mato Grosso do Sul (MS), Minas Gerais (MG), Pará (PA), Paraíba (PB), Paraná (PR), Pernambuco (PE), Rio Grande do Norte (RN), Rio Grande do Sul (RS), Tocantins (TO). 
than 10 children infected. Studies with less than 200 infected mothers could have a strong bias in relation to the rate of congenital transmission. Large studies were performed in only three countries (Argentina, Bolivia and Paraguay) and results from over 2,500 infected mothers gave a precise figure for the rate of transmission, which was remarkably similar between studies at 4-6\% (Carlier \& Truyens 2010, Howard et al. 2014).

In Brazil, studies are shorter and rates lower (Martins-Melo et al. 2014), begging the question: why? One reason is that the prevalence of congenital transmission in the last decade in Brazil is less than $1 \%$, so it was necessary to study 10,000 pregnant women to obtain 100 infected women and a few cases of congenital transmission. However, even in the few reports where more than 100 infected mothers were studied, the prevalence of congenital transmission was lower than in the three countries referred to above.

An opportunity to unravel this mystery arose from a study performed by our group for other purposes. A national serological survey was conducted between 20022008 by collecting 104,954 samples on filter paper from children born after insecticides were sprayed throughout the country (Luquetti et al. 2011). Roughly one in every three municipalities in all of Brazil (with the exception of RJ) was included. We found 20 cases in which samples from the children positive for $T$. cruzi correlated with the positivity of the mothers. This confirmation was performed by blood collection from the child and the mother, using the same methodology as in this report (4 serological tests). These cases were labelled as congenital because vectorial and other mechanisms of transmission were ruled out. The striking and unexpected finding was that the majority (12) of these cases were found in a single state, RS. In this state, only 4,529 samples of filter paper were collected, as opposed to all the other states that contributed with 100,425 samples (i.e., at BA 16,489 samples were collected, with a single congenital transmission). In all the other states combined, only eight cases of congenital transmission were observed. This makes the rate of transmission in the rest of Brazil.

Geographical differences in Chagas disease clinical manifestations are well known and recognised (Prata 1975). Megaesophagus is prevalent mainly in central Brazil (de Rezende \& Luquetti 1994). Mortality due to Chagas disease is higher in central Brazil, mainly GO and Minas Gerais. Specific treatment with nifurtimox (NFX) is less effective in Brazil than in other countries such as Chile and Argentina, however Prata et al. (1975) found a good response to the drug in RS. Cases of cardiopathy are recognised as infrequent in RS and cases of megaesophagus are mainly of group I, the less severe type (de Rezende \& Luquetti 1994). These features are similar for the countries bordering RS, Argentina and Uruguay. All of this evidence indicates a similarity of the disease patterns between RS and other countries and calls attention to potential differences in the host or the parasite within Brazil.

Recently, T. cruzi has been recognised to be divided into six different groups called discrete typing units (DTUs), from TcI to TcVI (Zingales et al. 2009). They belong to different ecotopes and have a geographical distribution as follows.
Tc I has mainly been found in humans at the north of the Amazonian River. This type of T. cruzi has also been found in vectors and occasionally in humans below the Amazonian River. Very few autochthonous cases of congenital infection from Colombia, Venezuela, Central America and Mexico have been described. Cases found in the USA were all imported from mothers born in South America. The related cases found in Europe (Spain, Switzerland) were all from mothers born mainly in Bolivia.

TcII has been found in humans mainly in central Brazil, associated with megaesophagus and severe cardiopathy. We published a 1986 paper in which all chronic phase patients harboured TcII, at the time known as zimodeme 2 (Luquetti et al. 1986). From recent isolations from our chronic patients with haemoculture, it has been determined that TcII had a higher prevalence (unpublished observations).

Tc III and IV are infrequent, found mainly in mammals in the sylvatic cycle in the Amazonian Region. Few cases have been described in humans, mainly in Venezuela. No cases of congenital transmission have yet been reported.

$\mathrm{TcV}$ is the main DTU found in humans to the south of the Amazonian River in Chile, Bolivia, Argentina, Paraguay, Uruguay and the south of Brazil (Corrales et al. 2009). All these countries report large numbers of cases and neonatal transmission has been higher, with prevalence values approximately $4 \%$ and $6 \%$.

$\mathrm{TcVI}$ has also been found in regions where $\mathrm{TcV}$ is present, but mainly in mammals and only occasionally in humans. A few reports of congenital transmission of TcVI have been reported thus far.

For the reasons outlined above, it is reasonable to propose that in central Brazil, where TcII is the main DTU isolated, this parasite subtype is responsible for the observed geographical differences in disease pattern, as evidenced by the high prevalence of megaesophagus and decreased efficacy of NFX in treated patients. Based on the results found in the current study, we suggest that TcII is also responsible for a lower rate of congenital transmission. These data are concordant with those found in the national survey and provide new evidence that the parasite subtype is an essential factor.

We conclude that in central Brazil, a region of TcII prevalence, congenital transmission is lower than in other countries of the South Cone and in other areas in the south of Brazil where $\mathrm{TcV}$ predominates. A relationship among TcII and lower congenital transmission is suggested. This is the first description of an association between a particular DTU (TcII) and the frequency of congenital transmission.

\section{ACKNOWLEDGEMENTS}

To Dr Daniela V Luquetti, for suggestions and English review.

\section{REFERENCES}

Barona-Vilar C, Gimenez-Marti MJ, Fraile T, Gonzalez-Steinbauer C, Parada C, Gil-Brusola A, Bravo D, Gómez MD, Navarro D, Perez-Tamarit A, Fernandez-Silveira L, Fullana-Montoro A, Borrás $\mathrm{R}$ 2012. Prevalence of Trypanosoma cruzi infection in pregnant Latin American women and congenital transmission rate in a non-endemic area: the experience of the Valencian Health Programme (Spain). Epidemiol Infect 140: 1896-1903. 
Botelho CAO, Tomaz CAB, Cunha RV, Botelho MAO, Botelho LO, Assis DM, Pinho DLM 2008. Prevalência dos agravos triados no programa de proteção à gestante do estado do Mato Grosso do Sul de 2004 a 2007. Rev Patol Trop 37: 341-353.

Carlier Y, Torrico F, Sosa-Estani S, Russomando G, Luquetti A, Freilij H, Viñas PA 2011. Congenital Chagas disease: recommendations for diagnosis, treatment and control of newborns, siblings and pregnant women. PLoS Negl Trop Dis 10: e1250.

Carlier Y, Truyens C 2010. Maternal-fetal transmission of Trypanosoma cruzi. In J Telleria, M Tibayrenc, American trypanosomiasis - Chagas disease. One hundred years of research, Elsevier, London/Burlington, p. 539-581.

Corrales RM, Mora MC, Negrette OS, Diosque P, Lacunza D, Virreira M, Breniere SF, Basombrio MA 2009. Congenital Chagas disease involves Trypanosoma cruzi sub-lineage IId in the northwestern province of Salta, Argentina. Infect Genet Evol 9: 278-282.

de Rezende JM, Luquetti AO 1994. Chagasic megavisceras. In Chagas disease and the nervous system, PAHO, Washington DC, p. $149-171$

Gomes Filho C, Macedo Filho JV, Gomes MM, Luquetti AO 2009. Expanded prenatal screening: the mommy test. Vita Sanitas 3: 101-109.

Howard EJ, Xiong X, Carlier Y, Sosa-Estani S, Buekens P 2014. Frequency of the congenital transmission of Trypanosoma cruzi: a systematic review and meta-analysis. BJOG 121: 22-33.

IBGE - Instituto Brasileiro de Geografia e Estatística 2014. Índice de/ organizacao_territorial/divisao_territorial/. Available from: geoftp. ibge.gov.br/organizacao_territorial/divisao_territorial/2014/.

Jackson Y, Delieutraz-Marchand J, Reis C, Benchouk M, Mauris A, Sizonenko S, Wyler C, Chappuis F, Diana A, Tejada BM 2009. Prevalence of Chagas disease among pregnant Latin American women and their newborns in Geneva, Switzerland. Trop Med Int Health 14: 238.

Luquetti AO, Miles MA, Rassi A, de Rezende JM, de Souza AA, Povoa MM, Rodrigues I 1986. Trypanosoma cruzi: zymodemes as- sociated with acute and chronic Chagas disease in central Brazil. Trans R Soc Trop Med Hyg 80: 462-470.

Luquetti AO, Passos AD, Silveira AC, Ferreira AW, Macedo V, Prata AR 2011. The national survey of seroprevalence for evaluation of the control of Chagas disease in Brazil (2001-2008). Rev Soc Bras Med Trop 44 (Suppl. 2): 108-121.

Luquetti AO, Schmuñis GA 2010. Diagnosis of Trypanosoma cruzi infection. In J Telleria, M Tibayrenc, American trypanosomiasis - Chagas disease. One hundred years of research, Elsevier, Amsterdam, p. 743-792.

Martins-Melo FR, Lima MS, Ramos Jr AN, Alencar CH, Heukelbach $\mathrm{J}$ 2014. Prevalence of Chagas disease in pregnant women and congenital transmission of Trypanosoma cruzi in Brazil: a systematic review and meta-analysis. Trop Med Int Health 19: 943-957.

OMS/OPS - Organización Mundial de la Salud/Organización Panamericana de la Salud 2006. Estimación cuantitativa de la enfermedad de Chagas en las Americas, OMS/OPS, Montevideo, 29 pp.

Prata A 1975. Reunião sobre diferenças geográficas na doença de Chagas, Escopo, Brasília, 433 pp.

Prata A, Macêdo V, Porto F, Santos I, Cerisola JA, Neiron S 1975. Tratamento da doença de Chagas pelo nifurtimox (Bayer 2502). Rev Soc Bras Med Trop 9: 297-307.

Schmunis GA 2007. Epidemiology of Chagas disease in non-endemic countries: the role of international migration. Mem Inst Oswaldo Cruz 102 (Suppl. I): 75-85.

Siriano LR, Luquetti AO, Avelar JB, Marra NL, de Castro AM 2011. Chagas disease: increased parasitemia during pregnancy detected by hemoculture. Am J Trop Med Hyg 84: 569-574.

Zingales B, Andrade SG, Briones MRS, Campbell DA, Chiari E, Fernandes O, Guhl F, Lages-Silva E, Macedo AM, Machado CR, Miles MA, Romanha AJ, Sturm NR, Tibayrenc M, Schijman AG 2009. A new consensus for Trypanosoma cruzi intraspecific nomenclature: second revision meeting recommends TcI to TcVI. Mem Inst Oswaldo Cruz 104: 1051-1054. 